Mens

Revue d'histoire intellectuelle et culturelle

\title{
Une lettre du journaliste Louis Francoeur au général Charles de Gaulle (7 septembre 1940)
}

\section{Mathieu Noël}

Volume 13, numéro 1, automne 2012

S'approprier le passé des autres : les usages de l'histoire internationale au Québec avant la Révolution tranquille

URI : https://id.erudit.org/iderudit/1019702ar

DOI : https://doi.org/10.7202/1019702ar

Aller au sommaire du numéro

Éditeur(s)

Centre de recherche en civilisation canadienne-française

ISSN

1492-8647 (imprimé)

1927-9299 (numérique)

Découvrir la revue

Citer cet article

Noël, M. (2012). Une lettre du journaliste Louis Francoeur au général Charles de Gaulle (7 septembre 1940). Mens, 13(1), 123-130.

https://doi.org/10.7202/1019702ar 


\title{
Document
}

\section{Une lettre du journaliste Louis Francoeur au général Charles de Gaulle (7 septembre 1940)}

\author{
Édition présentée par \\ Mathieu Noël \\ Université du Québec à Montréal
}

Pour renouer avec l'édition de documents d'archives inédits, le comité de rédaction de la revue Mens a choisi de vous présenter une lettre du journaliste et animateur de radio Louis Francoeur, envoyée au général Charles de Gaulle le 7 septembre 1940. En plus d'être inédit, ce document était jusqu'à maintenant inconnu, puisqu'il provient des archives privées de la famille de Louis Francoeur. Dans cette lettre, écrite peu après l'armistice signé entre la France et l'Allemagne le 22 juin 1940, Francoeur offre son appui au général de Gaulle et il témoigne du manque d'organisation des partisans de la «France libre » au Canada.

\section{Qui est Louis Francoeur ${ }^{1}$ ?}

Louis Francoeur est né le 3 avril 1895 à Montréal. Il se destine tout d'abord à la prêtrise. En 1913, il part en Belgique pour faire son

${ }^{1}$ Claude-Henri Grignon, "Louis Francoeur, toujours vivant ", Les pamphlets de Valdombre, vol. 4, no 11-12 (avril-mai 1941), p. 348-415; Blaise Orlier, 
noviciat auprès de la communauté bénédictine de Saint-Wandrille. Ses confrères et lui se retrouvent toutefois prisonniers des Allemands de 1914 à 1918. Quelque temps après la fin du conflit, il quitte la vie ecclésiastique. Après un séjour de quelques mois à Paris, où il travaille pour une maison d'édition, il revient au Québec et entreprend une carrière dans le journalisme. Dans les années 1920, il est courriériste parlementaire à La Patrie et au Montreal Star. Puis, en 1929, il s'installe à Québec où il est nommé directeur et rédacteur en chef du Journal, un hebdomadaire destiné à défendre les politiques conservatrices. Au début des années 1930, Francoeur milite activement au Parti conservateur. D'ailleurs, il est candidat aux élections provinciales de 1931 dans le comté de Montmorency, contre nul autre que le premier ministre sortant Louis-Alexandre Taschereau. En 1934, Francoeur retourne à Montréal pour occuper le poste de rédacteur en chef du quotidien L'Illustration, un autre journal de tendance conservatrice. Étant l'un des idéologues du réseau conservateur, il participe en 1935 à la rédaction du Catéchisme des électeurs, un texte de propagande, sous forme de questions-réponses, contre le Parti libéral du Québec.

En 1939, Francoeur fait ses débuts à la radio de Radio-Canada. À partir de l'été 1940, il anime l'émission quotidienne La situation ce soir dans laquelle il présente et commente les actualités liées à la Deuxième Guerre mondiale. Chaque soir, il rejoint ainsi des milliers de Canadiens français dans leurs foyers. La présence de Francoeur à la barre de La situation ce soir prend fin abruptement le 2 juin 1941, lorsqu'il succombe aux blessures qu'il a subies quelques jours plus tôt dans un accident d'automobile. Signe de sa popularité auprès des Canadiens français, environ 50000 personnes lui ont rendu un dernier hommage à l'Institut des sourdes-muettes à Montréal.

Louis Francoeur, journaliste, Ottawa, Les Éditions du Droit, 1941; "Hommage à Louis Francoeur ", Regards, juillet-août 1941, p. 193-223. 


\section{L'émergence des comités de la France libre au Québec}

Lors de l'armistice du 22 juin 1940, les Français sont divisés quant à l'attitude à adopter. Certains considèrent que ce n'est pas tant la défaite de la France, que celle de la Troisième République. Ils envisagent favorablement l'arrivée du maréchal Pétain et de son programme de "Révolution nationale ", dans lequel l'on retrouve une apologie des valeurs traditionnelles. D'autres, au contraire, refusent de voir la France sous le joug nazi. L’un d'eux est le général Charles de Gaulle, qui était sous-secrétaire d'État à la Défense nationale et à la Guerre sous le gouvernement de Paul Reynaud. Exilé à Londres, il lance aux Français un premier appel à la résistance le 18 juin 1940 sur les ondes de la BBC. Cet appel est l'acte fondateur du mouvement de la " France libre », qui réunit derrière le général de Gaulle les partisans pour la libération de la France. Pour atteindre son objectif, la France libre cherchera à fonder des comités d'appui dans les colonies françaises et les pays étrangers. La mission de ces comités était de réaliser de la propagande en faveur de la libération de la France et de récolter des souscriptions pour l'achat de matériel militaire destiné aux Forces françaises libres, soit l'armée du gouvernement en exil. Au Québec, le maréchal Pétain et le général de Gaulle reçoivent tous les deux des appuis; des groupes s'organisent pour soutenir un camp ou l'autre ${ }^{2}$. Un premier comité de soutien à la France libre est fondé à Québec au commencement de l'été $1940^{3}$. Il est présidé par Marthe Simard (1901-1993), une Algérienne née de parents français. En décembre 1940, ce groupe est officiellement reconnu comme un Comité de la France libre - il s'agit du premier comité à l'extérieur de la France à recevoir son accréditation. À

2 Selon Éric Amyot, les Canadiens français furent, de 1940 à 1942, majoritairement favorables à l'État français du maréchal Pétain (Éric Amyot, Le Québec, entre Pétain et de Gaulle: Vichy, la France libre et les Canadiens français : 1940-1945, Montréal, Éditions Fides, 1999).

3 Pour plus d'information sur le Comité France libre de Québec, voir Frédéric Smith, "La France appelle votre secours ": Québec et la France libre : 1940-1945, Montréal, VLB éditeur, 2012. 
Montréal, un groupe d'aide à la France libre est d'abord fondé par William Vignal à la fin du mois de juillet. Médecin d'origine française, il a immigré au Québec au début des années 1930. Il est également un ancien militaire et le président de l'Union nationale française de Montréal. Vignal est en contact direct avec le général de Gaulle. Pendant quelque temps, il est considéré comme le représentant du général au Canada ${ }^{4}$. Dans leurs fonctions, Marthe Simard et William Vignal reçoivent l'aide d'Élisabeth de Miribel (1915-2005), une jeune Française envoyée de Londres par le général de Gaulle en août 1940 pour recueillir des appuis en faveur de la France libre.

\section{L'entrée en scène de Louis Francoeur}

C'est quelque temps après l'appel à la résistance du 18 juin 1940 et dans une période où différents comités d'aide à la France sont fondés que le journaliste Louis Francoeur écrit au général de Gaulle. Il s’agit d'une lettre complaisante où l'auteur répète à quelques occasions son respect pour l'œuvre du général. Il lui offre aussi ses encouragements, notamment en citant l'exemple du « miracle canadien » de la résistance française en Amérique. La lecture de cette lettre permet de relever deux faits particulièrement intéressants. Premièrement, Francoeur témoigne du manque initial d'organisation des partisans de la France libre au Canada. Le motif de sa lettre est d'exprimer son « incertitude » quant à la représentation du général. Francoeur et ses amis souhaitent apporter leur contribution à la France libre, mais ils ne savent pas à qui s'adresser. Selon lui, " personne d'autorisé ne leur transmet de consigne ». Pourtant, lorsque Francoeur écrit sa lettre, le médecin William Vignal agissait déjà depuis quelques semaines en tant que représentant du général au Canada, en plus de présider le comité montréalais d'aide à la France libre. Le fait que Francoeur, alors le journaliste de Radio-Canada attitré à la couverture quotidienne de la Deuxième Guerre mondiale, ignore le rôle du docteur Vignal laisse croire que ce dernier avait de la difficulté à faire

${ }^{4}$ Ibid., p. 41. 
connaître son organisation et à rassembler autour de lui les partisans de la France libre ${ }^{5}$. C'est probablement pour ces raisons que Vignal sera remplacé, en mai 1941, par Jacques-Émile Martin-Prével (1892-1952) comme représentant du général de Gaulle.

D'autre part, la lettre nous apprend que Louis Francoeur appuie clairement le mouvement de la France libre dès le mois de septembre 1940. Le journaliste est même prêt à débourser de son argent personnel pour faire circuler une photographie du général. Ce soutien est loin d'être banal, puisqu'en 1940, Francoeur occupe une position stratégique qui lui permet d'influencer l'opinion publique. À la barre de l'émission La situation ce soir, il commente les actualités militaires sur une base quotidienne. Certains soirs, il prend quelques minutes pour critiquer le régime de Vichy, ou encore pour dénoncer ce qu'il appelle la " colonne $\mathrm{Q}$ ", soit les opposants à la participation canadienne à la guerre ${ }^{6}$. À d'autres occasions, Francoeur invite Élisabeth de Miribel à son émission pour discuter de la France libre et du général de Gaulle. Francoeur était donc un allié précieux pour le mouvement de la France libre qui espérait rallier les Canadiens français à sa cause, et Élisabeth de Miribel en était parfaitement consciente. Dans l'un de ses rapports, elle présente ainsi le journaliste à son supérieur : "Le plus écouté des Canadiens français. Entièrement pour nous, procède quotidiennement par insinuations de façon fort habile et n'hésite pas à prendre parti à l'occasion d'un document important ou d'une victoire en Afrique ${ }^{7}$. "Signalons que dans un autre de ses rapports, de Miribel affirme avoir elle-même convaincu Francoeur de joindre les rangs de la France libre ${ }^{8}$. Or la lettre du

5 Éric Amyot et Frédéric Smith expliquent, dans leur ouvrage respectif, que le mouvement de la France libre était alors paralysé au Canada par des querelles intestines.

6 Certaines causeries prononcées par Louis Francoeur dans le cadre de l'émission La situation ce soir ont été éditées : Louis Francoeur, La situation ce soir, vol. 1-12, Montréal, Roland Beaudry, 1941.

7 Lettre d'Élisabeth de Miribel à Geoffroy de Courcel, 11 février 1941, citée dans Smith, "La France appelle votre secours", p. 74.

8 Lettre d'Élisabeth de Miribel à Maurice Garreau-Dombasle, 12 janvier 1941, citée dans Amyot, Le Québec, entre Pétain et de Gaulle, p. 129. 
7 septembre montre que celui-ci était déjà un partisan du général de Gaulle avant de faire la connaissance de Miribel au début de l'année 1941. Francoeur y mentionne n'avoir jusqu'alors rencontré personne de la France libre apte à lui transmettre des consignes.

Bref, la lettre de Louis Francoeur au général de Gaulle nous informe que les partisans de la France libre sont mal organisés au Canada à l'été 1940 - ou à tout le moins, qu'ils ont de la difficulté à se faire connaître et à s'imposer comme groupe de pression. Nous notons également que Francoeur a adhéré rapidement au mouvement de la France libre. Notre analyse externe a montré qu'il y a joué un rôle clé au Canada. En terminant, mentionnons que nous n'avons pas trouvé de réponse du général de Gaulle dans les archives de la famille Francoeur. Ainsi, impossible de savoir si la lettre de Francoeur a bel et bien été lue par le général. Cela demeure néanmoins une possibilité, puisque Francoeur est mis en relation avec Élisabeth de Miribel, l'envoyée de la France libre au Québec, quelque temps après l'envoi de sa lettre.

\section{Personnelle}

M. le général de Gaulle

c/o War Office

London, England

Mon général,

Après vous avoir présenté mes hommages, je vous prie de me permettre une brève présentation. Je suis un journaliste canadien-français d'âge presque correspondant au vôtre, qui a vécu plusieurs années en France et qui n'exerce pas d'autre métier que celui d'écrire et de faire du journalisme à la radio.

Canadien de naissance, dont la famille émigra il y a plus de trois cents ans, j'ai aussi du sang écossais et anglais. Depuis le début de la présente guerre, on $\mathrm{m}^{\prime}$ a confié la traduction française des services 
de la B.B.C. pour l'Amérique du Nord. Sans être un grand chrétien, mes tendances sont plutôt de droite.

Tout ceci dit, vous pourrez obtenir des renseignements complémentaires de M. Gérard Arthur, qui est présentement affecté au service canadien de la B.B.C.

Ce qui m'amène à vous écrire est $l^{\prime}$ incertitude où nous sommes de votre représentation au Canada. Nous aimerions bien savoir qui a qualité pour parler en votre nom. Vous n'ignorez pas, mon général, que plusieurs Canadiennes et Canadiens ont reconstitué, sous une forme nouvelle, dès le début de la présente guerre, le Comité d'Aide à la France qui fit de bien utile besogne de 1914 à 1918. Ces dames et ces messieurs ne savent à qui $s^{\prime}$ adresser pour faire parvenir aux Français libres ce que leur générosité donne, trouve, invente ou confectionne.

S'il m'était permis de vous faire une respectueuse suggestion, peut-être y aurait-il moyen de nous faire savoir, à la radio ou par lettre, exactement à qui l'on doit $\mathrm{s}^{\prime}$ adresser, à Montréal, à Québec, ou à ottawa, si l'on veut faire parvenir quoi que ce soit à vos amis.

Nous sommes ici plusieurs qui aimons la France, à ce point qu'on oublie ceux qui la gouvernent. La plupart d'entre nous ont vécu en France, et tous sont très fiers de leur sang. Les malheurs de la patrie les affligent sans les démonter. Ils voudraient faire quelque chose, mais personne d'autorisé ne leur transmet de consigne.

$S^{\prime}$ il vous était possible de dire à toutes ces bonnes volontés comment elles peuvent $s^{\prime} y$ prendre pour traduire en actes leur ardente sympathie, nous vous en serions profondément reconnaissants. Peutêtre ne savez-vous pas, mon général, jusqu'à quel point vous avez parmi nous d'amis spontanés, que vous ne connâ̂trez jamais, qui admirent l'exceptionnelle noblesse de votre désintéressement, qui, en bien des cas, ont lu vos écrits, et qui sont animés d'une inébranlable confiance. 
Nous avons le grand honneur d'avoir accompli traditionnellement ce qu'on a appelé " le miracle canadien ». Conquis depuis 1763, année du traité de Paris, nous avons résisté à tout : persécutions, massacres, pendaisons, jusqu'à ce que $l^{\prime}$ on se fût convaincu que nous étions un petit peuple qui n'accepterait jamais. C'est ce qui fait que le miracle français que vous avez commencé nous touche instinctivement et nous incite à collaborer selon que les circonstances, la distance, le temps et les complications artificielles nous le permettent.

Je m'excuse, mon général, de vous avoir écrit de la sorte. Il y a longtemps que j'y pensais. Ma personne $\mathrm{n}^{\prime}$ a aucune importance, mais le fait que je suis entendu deux fois par jour par le tiers du continent nord-américain, depuis le sommet des bancs de Terre-Neuve jusqu'à Chicago, et de Philadelphie jusqu'au nord de la province d'ontario, me force quelque peu la main...

Encore une fois, vous pourrez obtenir sur mon humble personne des renseignements d'élémentaire prudence. M. Désy, notre ministre à Bruxelles, est présentement à Londres, me dit-on; c'est un de mes amis d'enfance. Et je suis certain que plusieurs des officiers canadiens de langue française connaissent au moins mon nom.

Avec les voux de tous ceux que je connais et les remerciements de ceux qui tiennent au Nouveau Monde les avant-postes français, j'ai l'honneur, mon général, de vous prier d'accepter mes hommages les plus déférents.

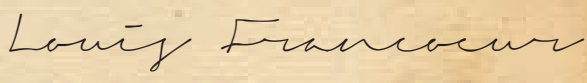

P.S. - Aucun journal canadien, apparemment, $\mathrm{n}^{\prime} \mathrm{a}$ de vous d'autre photographie que celle-là qui vous représente en képi de service aux trois étoiles. Si vous me faisiez l'honneur de me faire parvenir la photo de vous-même que vous jugez la meilleure, ce serait un plaisir pour moi que d'en faire confectionner des matrices que j'expédierais à mes frais à nos journaux. 